\title{
Etnicidad y exclusión social en Colombia en el período 2012-2017
}

\author{
Edinson Ortiz Benavides y José Javier Núñez Velásquez
}

\section{Resumen}

La presente investigación tiene por objeto ofrecer una aproximación a conceptos y formas de medir la etnicidad y la exclusión social que se puedan generalizar a todo contexto y tiempo y que, por ende, permitan establecer una relación estadísticamente significativa entre estas categorías. La información que se utiliza para implementar la propuesta metodológica proviene de la Encuesta Nacional de Calidad de Vida de Colombia correspondiente al período 2012-2017. Se utilizan conjuntos difusos y mínimos cuadrados ordinarios con un 95\% de confianza, y se concluye que cuando la etnicidad se incrementa 1 punto porcentual, el grado de exclusión social aumenta 7 puntos porcentuales en el país. Otras características, como tener un tono de piel más oscuro, autoadscribirse a un grupo étnico, pertenecer a la categoría de inmigrante y vivir en zonas rurales, van en la misma dirección.

\section{Palabras clave}

Etnicidad, pueblos indígenas, afrodescendientes, grupos étnicos y raciales, derechos económicos, sociales y culturales, pobreza, ingresos, aislamiento social, medición, integración social, política social, Colombia

\section{Clasificación JEL}

$$
\text { J10, J15, I32, F22 }
$$

\section{Autores}

Edinson Ortiz Benavides es Profesor Asociado en el Departamento de Economía de la Universidad de Nariño (Colombia) y Doctor por la Universidad de Alcalá (España). Correos electrónicos: edinson.ortiz@uah.es, edinson@udenar.edu.co.

José Javier Núñez Velásquez es Profesor Titular en el Departamento de Economía de la Universidad de Alcalá (España). Correo electrónico: josej.nunez@uah.es. 


\section{Introducción}

La etnicidad y la exclusión social son dos categorías sobre cuya conceptualización, medición e interrelación no existe el consenso suficiente, pues si bien son expresiones que se acuñaron hace poco tiempo, sus raíces pueden encontrarse siglos atrás en la sociología, la biología o la antropología. En esta investigación no se pretende hacer un compendio sobre el tema, sino, por un lado, ofrecer una aproximación a conceptos y formas de medir estos fenómenos que se puedan generalizar a cualquier contexto y tiempo y, por otro lado, establecer una relación estadísticamente significativa entre ambos.

La idea de raza, etnia e inmigración, junto con el género, la clase, la edad y la religión, sustenta "variados sistemas y mecanismos culturales, económicos y sociales de dominación a través de los cuales se impide el acceso equitativo de grandes grupos humanos al disfrute de bienes simbólicos y de consumo" (Bello y Rangel, 2000, pág. 4). "Los análisis y las investigaciones realizados en las dos últimas décadas sobre la exclusión social, la pobreza y la desigualdad en América Latina han puesto de relieve la situación de desventaja y marginación de la población indígena y los grupos afrodescendientes -la misma que tiene como punto de origen el colonialismo y el sistema esclavista del cual fueron víctimas"(Valdivia, 2011, pág. 20). Se ha llegado así a reconocer la existencia de ciertas "brechas étnicas" que ponen de relieve la diferencia en cuanto al grado y el modo en que los grupos étnico-raciales afrontan los problemas de pobreza y exclusión social (Valdivia, 2011, pág. 20).

Mediante la utilización de información estadística proveniente de la Encuesta Nacional de Calidad de Vida de Colombia correspondiente al período 20122017, se busca aproximar los conceptos a las categorías disponibles en los datos, y establecer la evolución de estos fenómenos y las relaciones entre ellos en ese período. Con ese fin, el presente artículo se ha dividido en cinco secciones: la primera contiene la introducción; en la segunda se aborda la etnicidad, su evolución conceptual y el establecimiento de un indicador (el factor de etnicidad o fet); en la tercera se tratan los aspectos y la complejidad de la exclusión social, y se propone una forma alternativa de medirla a partir del grado de exclusión social (ges); en la cuarta se muestran los resultados a partir de los indicadores establecidos, así como la evolución y la relación entre ellos, y en la quinta y última sección se exponen las principales conclusiones de esta investigación.

\section{Etnicidad: categoría social y económica}

\section{El concepto de etnicidad}

Aunque el concepto de etnicidad surgió hace medio siglo, no hay consenso en cuanto a él, y el avance hacia su concreción es marginal, al punto de que se confunde abiertamente con las nociones de raza y grupo étnico, que se aspiraba a superar. Desde que el sociólogo norteamericano David Riesman mencionara el concepto por primera vez en 1953, la etnicidad se ha asociado con la cultura de pertenencia, la desigualdad, la discriminación y la dominación de un grupo social sobre otro en razón de una supuesta superioridad o sobre la base de derechos mejores y más legítimos que los de las personas que se desvalorizan y excluyen (Oommen, 1994). Al igual que otras categorías, como el género y la clase, la etnicidad sustenta variados sistemas y mecanismos institucionales, culturales, económicos y sociales de dominación a través de los cuales se impide que grandes grupos humanos que son objeto de marcados y reiterados procesos de exclusión social accedan de forma equitativa al disfrute de bienes simbólicos y de consumo (Bello y Rangel, 2000).

De conformidad con lo anterior, la etnicidad es una categoría que se construye socialmente y que tiene fuertes implicaciones económicas. A su vez, alberga otras categorías que establecen diferencias 
entre los grupos poblacionales en un contexto y un tiempo determinados. Esas categorías son la raza, la etnia y la inmigración, que son componentes esenciales de la etnicidad y que juntas representan los mayores elementos de discriminación y exclusión social en un país.

\section{Los componentes de la etnicidad}

\section{a) La raza}

La raza es la primera categoría o componente de la etnicidad y es un concepto construido para justificar las diferenciaciones fenotípicas entre los seres humanos. Este concepto comprende la división taxonómica del género humano a partir de diferenciaciones biológicas, morfológicas y fisiológicas. Empero, de acuerdo con Stavenhagen (2002), el término raza se ha utilizado "no como un referente biológico demostrado empíricamente, sino como una construcción social que toma como criterios de clasificación algunos rasgos biológicos visibles". Esto ha ocurrido pese a que la biología genética ha demostrado que en la especie humana no hay tal división racial, y que más bien todos los seres humanos comparten los mismos rasgos biológicos. (Antón y Del Popolo, 2009).

Al respecto, Wade (2011) señala tres teorías sobre el significado de raza. En cuanto a la primera, dice que "tiene que ver con la variación genética humana. Es claro que los seres humanos varían su constitución biológica en algunas formas muy evidentes. La pregunta es si dicha variación puede clasificarse en un número discreto de categorías definidas, llamadas 'razas', cada una de las cuales tiene una serie de características comunes, como el color de la piel, el tipo de cabello, el grupo sanguíneo o aspectos de la constitución genética. Si así fuera, el concepto de raza sería útil para hablar sobre las variaciones en la naturaleza humana. De hecho, ese es precisamente el significado de raza que predominó en los círculos populares y científicos occidentales a lo largo del siglo XIX y durante buena parte del siglo XX" (Wade, 2011, pág. 208).

En lo que respecta a la segunda teoría, Wade (2011) señala lo que se indica a continuación: "La segunda teoría, más controvertida, sostiene que la variación superficial de la apariencia externa tiene correlación con otras características humanas. El color de la piel tiene una fuerte influencia de los genes heredados por el individuo; la pregunta es si esos mismos genes, o alguna parte correlacionada del complemento genético, ejercen también una influencia significativa en habilidades cognitivas como 'la inteligencia' o quizás en habilidades como la fuerza o la velocidad. Esta segunda teoría le cayó como anillo al dedo a la primera y también predominó en el siglo XIX y en buena parte del siglo XX. Una 'raza' podía definirse no solo en términos de aspectos de la biología como el color de la piel y los rasgos faciales, sino también en términos de las características morales e intelectuales” (Wade, 2011, pág. 209).

En relación con la tercera teoría, Wade (2011) afirma lo siguiente: "La tercera teoría sobre la raza sostiene que, sea cual sea la variación genética humana existente, no puede describirse de manera útil en términos de raza y que la raza es una idea, sin relevancia biológica en el potencial humana. Su condición como idea, sin embargo, no denigra de su enorme importancia social. Aun cuando la raza no tenga ninguna base biológica en la naturaleza humana, las personas están claramente preparadas para discriminar a otros que definan como racialmente diferentes. [...] Esta tercera teoría se basa en la idea actualmente aceptada de que 'las razas' son construcciones sociales, pero reconoce que eso no evita que la raza sea una noción muy importante y a menudo profundamente arraigada que afecta en formas sustanciales el comportamiento de la gente y sus oportunidades" (Wade, 2011, págs. 209 y 210).

Rangel (2004) también hace referencia a esta tercera teoría y afirma lo que se indica a continuación: "A partir de comienzos del siglo XX, con la creciente aceptación de las teorías que despreciaban las clasificaciones morfológicas de los seres humanos, el concepto de raza perdió su importancia científica, 
siendo parcialmente abandonado. La biología empezaba a reconocer la inexistencia de subdivisiones de la especie humana que pudieran justificarse a partir de factores genéticos, y a las cuales corresponderían determinadas cualidades físicas, sicológicas, morales o intelectuales distintas. Se advertía entonces que las diferencias entre los grupos humanos sólo podían explicarse científicamente a partir de su origen histórico y cultural, ante lo que cobraba mayor importancia analítica el concepto de etnia, en sustitución del de raza" (Rangel, 2004, págs. 31 y 32).

\section{b) La etnia}

El concepto de etnia como segundo componente de la etnicidad se deriva de la voz griega ethnos, que a su vez deriva del término ethnicus. La voz ethnos originalmente significaba pueblo o nación y se utilizaba indistintamente como reemplazo de la desprestigiada categoría raza para caracterizar a los grupos étnicos o a las identidades étnicas que integraban esos grupos. Según Valdivia (2011), recientemente la conceptualización étnica se ha desarrollado más que nada a través de dos grandes vertientes teóricas. La primera se conoce con el nombre de enfoque primordial, y según ella los grupos étnicos se definen a partir de las características propias e inherentes a su cultura, como la lengua, la música, las costumbres, los ancestros, la vestimenta, las instituciones y los valores, entre otras. En la segunda vertiente teórica se vinculan varias posturas que surgieron en oposición a lo que se ha denominado "primordialismo". Dichas posturas se agrupan en un enfoque contextual o circunstancial y comparten dos ideas básicas: "En primer lugar, no existen identidades étnicas predefinidas e inmutables, dado que la identidad es dinámica y está sujeta a los cambios del desarrollo histórico de los grupos. Y, en segundo término, las identidades dependen en gran medida del entorno social, político y cultural en el que se desarrollan los pueblos o grupos involucrados, por lo que obedecen a ciertos posicionamientos estratégicos definidos a partir del contexto" (Valdivia, 2011, pág. 30).

En general, en las definiciones convencionales sobre identidad étnica se "suelen recoger elementos de ambas perspectivas -la 'primordialista' y la 'circunstancial' o 'constructivista'-. En ese sentido, el concepto de 'grupo étnico' suele hacer referencia a aquella comunidad que comparte un pasado (tradición), una cultura y una forma de organización social, la cual además se percibe y es percibida por otros como un colectivo con atributos sociales y elementos culturales en común (idioma, religión, nacionalidad o 'raza'). Su existencia supone valores y creencias compartidos, e involucra la vigencia de un sentimiento común de identidad" (Valdivia, 2011, pág. 32).

La etnia, entonces, implica un grupo étnico, entendido como una comunidad que no solo comparte una identidad racial, sino que además se autorreconoce como tal y comparte costumbres, territorio, creencias, cosmovisión, y noción idiomática o dialectal y simbólica. Pero un grupo étnico entendido en estos términos no supone que en el grupo o la comunidad haya homogeneidad de clases, política y económica. Este término solo permite redefinir la identidad colectiva. Es decir, en un grupo étnico o una etnia hay diferenciaciones sociales, económicas y políticas propias, pero a la vez se mantiene una fortaleza como grupo cultural tanto hacia dentro como hacia fuera (Hopenhayn y Bello, 2000).

\section{c) La inmigración}

En el marco de la presente investigación, la inmigración -entendida como el fenómeno en que la residencia habitual de las personas cambia de un país a otro- constituye el tercer componente de la etnicidad. Esto se debe a que, al traspasar fronteras políticas, los grupos poblacionales adoptan características de grupos étnicos y tanto ellos mismos como la sociedad de acogida los perciben de ese modo. Estos grupos poblacionales pueden proceder de una región, un país o un grupo de países determinados, como es el caso de la comunidad hispana en los Estados Unidos. 
La inmigración así entendida es un fenómeno que ha estado presente a lo largo de la historia de la humanidad, ha condicionado la configuración de los pueblos y más tarde de los Estados, y ha dado lugar a grandes disparidades entre los países más y menos desarrollados del mundo en lo que atañe a las circunstancias socioeconómicas, las oportunidades y la seguridad humana. "Sin embargo, las migraciones que han tenido lugar desde principios del siglo XXI no tienen precedentes, ya que recientemente éstas han alcanzado su mayor volumen en la historia y presentan características que las diferencian de las observadas en periodos anteriores, lo que ha propiciado una nueva conceptualización del fenómeno, enmarcada en lo que algunos estudiosos llaman 'la nueva era' de las migraciones internacionales" (Arango, 2003, citado en Godínez-Montoya, Figueroa-Hernández y Pérez-Soto, 2014, pág. 13).

Esta nueva era se circunscribe en "un escenario de globalización económica, cultural e informacional, que estimula que segmentos amplios de la población respondan cada vez más rápidamente a informaciones y oportunidades que se originan más allá de las fronteras nacionales" (CONAPO, 2009, citado en Godínez-Montoya, Figueroa-Hernández y Pérez-Soto, 2014, pág. 13). Estos factores, asociados con la desigualdad en cuanto a la distribución de la actividad económica, el ingreso y la pobreza, así como con las crisis económicas, políticas o bélicas, facilitan los movimientos migratorios. Esto ocurre porque las personas, que se encuentran en una constante búsqueda del bienestar económico, la seguridad y una mejor posición social presente y futura, observan, en ocasiones con mucha tristeza, que en sus países de origen difícilmente conseguirán alcanzar esas metas (Peligero Escudero, 2006).

En el caso latinoamericano en particular, las crisis políticas y económicas dan lugar a incertidumbre sobre el futuro de los países y las personas. "Si bien es cierto que, como registran los datos de la CEPAL [(2008)], las tendencias de crecimiento económico, disminución de la pobreza y generación de empleos han sido positivas en los últimos años, la sensación de incertidumbre que genera la región no se disipa con algunos buenos años económicos. Los problemas estructurales de la economía latinoamericana siguen estando presentes como, por ejemplo, la dependencia y la vulnerabilidad de las economías domésticas, las disparidades entre las distintas regiones al interior de los países, la desigualdad entre las distintas clases sociales, la desigual distribución del ingreso y la carencia de servicios públicos eficientes" (Tedesco, 2010, pág. 123).

\section{La medición de la etnicidad en la práctica}

A nivel mundial, pero con mayor énfasis en América Latina, cada vez hay más consenso sobre la necesidad de dar visibilidad a los diferentes grupos étnicos que viven dentro de las fronteras "a fin de identificar sus problemas y sus necesidades, brindarles el reconocimiento debido y otorgarles un papel protagónico en las decisiones relacionadas con su propio desarrollo. En ese sentido, se han implementado iniciativas orientadas a la identificación étnico/racial en las estadísticas oficiales generadas en varios países, a fin de contar con información que sirva para diseñar y desarrollar políticas de inclusión social que tomen en cuenta la problemática social, económica, política y cultural de esos grupos históricamente excluidos" (Schkolnik y Del Popolo 2006, pág. 249, citado en Valdivia, 2011, págs. 19 y 20).

En América Latina, los avances son evidentes desde 1990 y sobre todo a partir del presente siglo. En los últimos años se han llevado a cabo iniciativas orientadas a crear sistemas de indicadores sobre la situación social y económica de los grupos étnicos, concepto que constituye el segundo componente de la etnicidad y que suele confundirse con el de raza e inmigración. Un ejemplo de ello son las categorías negro, mulato, afrohispano, blanco-hispano, chino y otras que se utilizan en algunos censos de la región.

Si bien hay interés en visibilizar las características generales de los grupos étnicos que hay en los países, existen varios desafíos que dificultan la comparabilidad internacional de los datos y que se relacionan con las definiciones conceptuales y metodológicas. Las estimaciones relativas a la población 
indígena y afrodescendiente, por ejemplo, han sido históricamente controversiales, tanto por la escasez de información confiable como por la diversidad de criterios a partir de los cuales se han hecho las estimaciones. En muchos casos se ha visto también que la información obtenida de los censos, sobre todo en las décadas de 1980 y 1990, difiere en porcentajes muy altos de otras estimaciones obtenidas por las autoridades étnicas y por estudiosos del tema en los mismos períodos o entre los períodos censales (Schkolnik, 2009).

En la gran mayoría de los países latinoamericanos se incluyen conjuntamente categorías de autoadscripción étnica y categorías raciales o de inmigración, no solo entre las categorías de respuesta, sino, en algunos casos, también en el enunciado mismo de la pregunta (Schkolnik, 2009). "Las consecuencias que esto puede tener sobre la cuantificación de los grupos étnicos depende del contexto sociocultural y geográfico de cada país; por lo tanto, son múltiples los sesgos derivados de las decisiones operativas adoptadas en el censo, las que pueden o no haber contado con la participación de los mismos pueblos indígenas, afrodescendientes u otros durante el proceso de discusión previo a la ejecución del censo" (Schkolnik, 2009, pág. 85).

Dada la importancia que tiene incluir las estadísticas étnicas como vía para formular políticas públicas destinadas a mejorar las condiciones de vida e inclusión social de estas poblaciones en los países del mundo en general y de América Latina y Colombia en particular, es preciso depurar los instrumentos de recolección de datos a fin de desligar totalmente la categoría étnica de las de raza e inmigración, y considerar esas tres categorías como componentes esenciales de un concepto mayor, a saber, el de etnicidad.

\section{El factor de etnicidad: propuesta metodológica}

Más allá de los consensos alcanzados, en el transcurso de las últimas tres décadas en general se ha observado un creciente reconocimiento de la complejidad y la importancia del tema étnico. "Por un lado, ha habido quienes han cuestionado la posibilidad de 'medir' la etnicidad a través del uso de categorías discretas e incluso dicotómicas" (Valdivia, 2011, pág. 52). De modo similar, "hay quienes sostienen que dado el carácter eminentemente político y contextual de las definiciones y categorías étnicas utilizadas en los censos de cada país, resulta inviable o -en todo caso- relativo establecer un solo enfoque a ser aplicado a nivel mundial” (Morning, 2008, pág. 28, citado en Valdivia, 2011). "Y ello es así porque las definiciones de los cuestionarios y preguntas censales sobre etnia/raza dependen de las interpretaciones políticas, las agendas y las motivaciones que lleva a los Estados de cada país a emprender esa tarea" (Valdivia, 2011, pág. 45).

Como estrategia para superar lo anterior es preciso redefinir los cuestionarios censales o de las encuestas de hogares a fin de desligar los elementos integrantes de la etnicidad y reunificarlos en una medida integral de etnicidad que aquí se denomina factor de etnicidad (fet).

Para construir este factor de etnicidad es necesario definir una variable para cada una de las categorías o componentes de la etnicidad, variable que se pueda adaptar a cualquier país, que sea categórica y que sea llevada a una única escala de valoración que la vuelva comparable. A continuación se lleva a cabo esa tarea de definición.

\section{a) Definición de la variable correspondiente a la raza}

En la actualidad, en los cuestionarios de la gran mayoría de los países la etnia y la raza se vinculan en las mismas preguntas. Esto ocurre, por ejemplo, con las categorías negro, blanco, mestizo e indígena, entre otras, en que se hace referencia indistinta al color de piel de las personas y a su adscripción a un determinado grupo étnico. 
En el cálculo del factor de etnicidad se propone utilizar el color de piel (cp) como variable a partir de la tonalidad imputada $(R)$ por el encuestador. Se sabe que, aunque en la actualidad está científicamente comprobado que no se puede aplicar el concepto ni la concepción de raza para clasificar a la especie humana, también es cierto que el color de las personas tiene utilidad instrumental para discernir cómo se distribuyen las oportunidades en las sociedades. Asimismo, es importante mencionar que, en lo que respecta a varios indicadores de bienestar, la clasificación o imputación externa del encuestador con base en la paleta de colores (del más claro al más oscuro) ha resultado ser un mejor predictor de las inequidades étnico-raciales que la autoclasificación, ya sea étnica o racial (Telles, 2014).

A modo de ejemplo cabe mencionar el Proyecto sobre Etnicidad y Raza en América Latina (PERLA), que se llevó a cabo en 2010, estuvo a cargo del Profesor Edward Telles, de la Universidad de Princeton, y constituyó un esfuerzo destinado a recopilar y analizar datos de encuestas para explorar una amplia gama de asuntos étnico-raciales en la región. Como parte del proyecto se hizo una encuesta que se aplicó en cuatro países (Brasil, Colombia, México y Perú) y que proporcionó datos muy necesarios para determinar las condiciones que había en la región. A partir de la encuesta, Telles y Steele (2012) muestran que, en casi todos los países de la región el tono de la piel está asociado con las oportunidades educativas, medidas en número de años de estudio. En otras palabras, como dicen los autores, las sociedades latinoamericanas son "pigmentocracias" en las que el color de la piel (junto con la clase social, el género y otros factores) afecta las oportunidades que se tienen en la vida.

En la escala cromática que se empleó en la encuesta del PERLA había 11 tonalidades de piel que iban de la más clara a la más oscura. En el fet se retoma esta escala y se da a $R$ el valor 0 para el color de piel más claro y 10 para el más oscuro. En este sentido se propone utilizar, al estilo de la encuesta del PERLA, una pregunta que pueda ser común a todos los países, en la que el encuestador asigne un número entre 0 y 10 al color de piel del encuestado. También podría usarse un colorímetro, pues ya ha quedado demostrada la posibilidad científica de medir la pigmentación de la piel. El colorímetro devuelve una valoración del color de piel que va del 0 al 100, donde 0 es el color más oscuro y 100 es el más claro.

Así las cosas, a fin de normalizar las variables de modo que tengan un valor entre 0 y 1 , para obtener el componente correspondiente al color de piel $(c p)$ se utiliza la siguiente ecuación:

$$
c p=R / 10
$$

\section{b) Definición de la variable correspondiente a la etnia}

Respecto a la identificación de grupos étnicos en los cuestionarios censales, en las últimas décadas ha habido una tendencia a incorporar preguntas de autoadscripción, aunque todavía prevalece una gran heterogeneidad en la forma de formular las preguntas, en las categorías que se incorporan a las respuestas, y en la adaptación de los conceptos y las metodologías a cada realidad nacional. Esto condiciona los resultados. En cierto sentido, se puede decir que las complejidades de usar las categorías étnico-raciales, así como las diferentes formas de medir y abordar esa dimensión, explican en gran medida por qué los resultados de las magnitudes y las proporciones que aparecen en cada clasificación étnico-racial muestran notables niveles de divergencia en los mismos contextos y tiempos (Schkolnik, 2009).

En la práctica, la autoadscripción étnica se complementa con la lengua materna y el idioma, la cultura y las costumbres, los rasgos físicos y la pertenencia a un pueblo, entre otros. Por su parte, dado el consenso internacional que hay al respecto, en el cálculo del factor de etnicidad se propone utilizar la autoadscripción a un grupo étnico (age) como variable, porque ella constituye el único criterio en que se respeta la dimensión subjetiva de los encuestados y, por tanto, es el criterio menos etnocéntrico. Además, este criterio se caracteriza por ser, al menos en el plano teórico, el más abarcador, ya que 
incluye a todas las personas que se declaran como miembros de un grupo étnico más allá de lo que cada una considere sobre el significado del término (Goldberg, 2007, pág. 7). A partir de este autorreconocimiento de la identidad como una de las dimensiones básicas para el tratamiento de los grupos étnicos, se podría ahondar en las demás cuestiones sobre origen común, cultura y territorialidad.

Una pregunta que permitiría establecer esta variable en el caso de Colombia sería la siguiente:

De acuerdo con su cultura, pueblo o rasgos físicos, ¿es usted miembro o se reconoce como miembro de alguno de los siguientes grupos étnicos?

a) Indígena

b) Gitano o rom

c) Afrodescendiente

d) Ninguno de los anteriores

Si la respuesta es a), hay que preguntarle además al encuestado a qué pueblo pertenece, y si habla la lengua materna. Si la respuesta es b), hay que preguntarle si habla la lengua romaní. Si la respuesta es c), hay que preguntarle a qué pueblo pertenece (raizal del Archipiélago de San Andrés, palenquero o afrocolombiano), y si habla la lengua materna.

Estas preguntas serían extensibles a otros países latinoamericanos, y también podrían adaptarse sin mayores esfuerzos a los países norteamericanos, europeos, asiáticos y africanos, porque en todos ellos hay grupos étnicos reconocidos.

La variable age toma valores dicotómicos: 1, si la persona se autoadscribe a algún grupo étnico (a, b, c), o 0, si la persona no se autoadscribe a ningún grupo (d).

\section{c) Definición de la variable correspondiente a la inmigración}

Como se ha mencionado, cuando las personas traspasan sus fronteras nacionales en colectivos importantes, los miembros de esos colectivos se autorreconocen como tales y se muestran hacia el exterior conforme a los rasgos culturales y demás elementos materiales e inmateriales (simbólicos) que comparten. Este hecho da lugar a un sentimiento de pertenencia o identidad grupal que es fundamental para la reproducción social del colectivo (Fernández de Labastida, s/f, pág. 2).

Precisamente, la etnicidad constituye el proceso social que reactiva "las identidades colectivas y los sentimientos de adscripción en torno a una serie de rasgos culturales comunes. Las personas que tienen una misma identidad étnica pueden compartir además unos rasgos físicos o no, pero lo que define realmente al grupo étnico es el sentimiento de pertenencia que acompañan todos sus miembros y la diferencia o contraste con respecto a otros grupos. Este tipo de sentimiento colectivo prolifera en determinados contextos donde conviven varias culturas y comunidades. En este sentido, la globalización económica está reactivando la etnicidad en tanto que una de sus consecuencias más directas es la intensificación de la migración a escala mundial” (Fernández de Labastida, s/f, pág. 3).

Como consecuencia de la inmigración, en un mismo espacio coexisten personas provenientes de diferentes culturas que constituyen grupos sociales diferenciados. La relación entre estos grupos es habitualmente asimétrica: la sociedad de acogida o comunidad receptora es el grupo dominante, y el colectivo de inmigrantes, el grupo subordinado. Surgen así relaciones entre minorías y mayorías que indican la posición social o la importancia estructural de cada grupo. Un grupo minoritario es el que, independientemente del número de personas que lo integren, vive en situación de inferioridad y subordinación respecto al grupo mayoritario, que es el que detenta el poder. En cualquier caso, la inmigración genera y reactiva la etnicidad porque supone la introducción de un otro (el inmigrante) en un territorio y en una cultura que se identifica con el nosotros (Blanco, 2000, pág. 108). 
A los efectos de calcular el factor de etnicidad, la variable inmigración (im) se incorpora definiendo la nacionalidad del encuestado y de sus padres. Con este fin es necesario averiguar si el encuestado jefe de hogar no ha nacido en el país donde se aplica la encuesta ( jfb), si la madre del encuestado no ha nacido en dicho país $(\mathrm{mb})$ y si el padre del encuestado tampoco lo ha hecho (pb). Cada una de estas variables dicotómicas toma el valor de 1 en caso afirmativo y de 0 en caso negativo. Con estos valores se calcula la variable inmigración (im), de la siguiente manera:

$$
i m=0,5 * j f b+0,25 * m b+0,25 * p b
$$

\section{d) Cálculo del factor de etnicidad}

Definidas las tres variables que integran el factor de etnicidad, los valores que estas podrían tomar son los que se indican en el cuadro 1.

Cuadro 1

Variables que integran el factor de etnicidad y valores que pueden tomar

\begin{tabular}{ll}
\hline Variable & Valores \\
\hline Color de piel $(c p)$ & {$[0]:$ tono de piel muy claro } \\
& {$[0-1]$ : tonos de piel intermedios } \\
& {$[1]:$ tono de piel muy oscuro } \\
\hline Autoadscripción a un grupo étnico (age) & {$[0]:$ el jefe de hogar no se autoadscribe a ningún grupo étnico del país } \\
& {$[1]:$ el jefe de hogar se autoadscribe a algún grupo étnico del país } \\
\hline Inmigración (im) & {$[0]:$ el jefe del hogar y ambos padres nacieron en el país en que se aplica la encuesta } \\
& {$[0,25]:$ el jefe de hogar nació en el país en que se aplica la encuesta y solo uno de sus padres } \\
& es extranjero \\
& {$[0,5]:$ ambos padres o el jefe de hogar son extranjeros [0,75]: el jefe de hogar y solo uno de } \\
& sus padres son extranjeros \\
& {$[1]:$ el jefe de hogar y ambos padres son extranjeros } \\
\hline
\end{tabular}

Fuente: Elaboración propia.

La ecuación que se utiliza para calcular el factor de etnicidad es la siguiente:

$$
f e t_{i}=\frac{\sqrt{c p_{i}^{2}+a g e_{i}^{2}+i m_{i}^{2}}}{\sqrt{c p^{2}+a g e^{2}+i m^{2}}} \rightarrow f e t_{i}=\frac{\sqrt{c p_{i}^{2}+a g e_{i}^{2}+i m_{i}^{2}}}{\sqrt{3}}
$$

donde:

fet $_{i}=$ factor de etnicidad del hogar $i ; c p_{i}=$ color de piel del jefe del hogar $i ;$ age $_{i}=$ autoadscripción a grupo étnico por parte del jefe del hogar $i ; i m_{i}=$ condición de inmigración del jefe del hogar $i$, y 1 es el valor máximo que pueden alcanzar cada una de las variables de etnicidad (cp, age e im).

Los valores del fet van del 0 al 1 . Cuanto mayor es el valor del fet, mayor es la etnicidad del hogar. Este indicador permite establecer y comparar valores de etnicidad en diferentes contextos. Por ejemplo, permite establecer qué hogar, ciudad o país es más étnico que otro y, por tanto, está o no está más expuesto a determinados fenómenos, como la exclusión social o la pobreza.

\section{Exclusión social}

\section{El concepto de exclusión social}

La exclusión social es un concepto muy dinámico que aparece como fenómeno exclusivo de las sociedades posindustriales o avanzadas que son fruto de un mayor desarrollo global, tecnológico 
y económico, y en las que, tras la crisis y posterior reestructuración del Estado de bienestar, se ha producido un cambio en el contrato social, de tal forma que el asistencialismo de la nueva etapa sociopolítica no garantiza la integración de todas las clases sociales (Raya Díez, 2006, pág. 30, citada en Hernández Pedreño, 2008)

Este concepto, aunque nuevo para la ciencia económica, no lo es para la sociología y conlleva las ventajas y los desafíos que todo enfoque de procesos supone. Su riqueza está dada por la multidimensionalidad, pero, al mismo tiempo, deja mucho espacio para que surjan divergencias entre los analistas, como señala Trouillot (2000, pág. 111). En ese sentido, "la exclusión social es un concepto y un fenómeno aún en construcción y reconstrucción por las ciencias sociales, prueba de ello es la dispersión de acepciones y discursos que denotan diferentes realidades para un mismo proceso" (Hernández Pedreño, 2008, pág. 29).

En concreto, "la exclusión social se puede definir como un conjunto de mecanismos estructurales [e institucionales] que impiden [de forma sistemática] a ciertos grupos sociales participar plenamente en las esferas económica, social, política y cultural de la sociedad" (Valdivia, Benavides y Torero, 2007, pág. 604). "Estos mecanismos ocasionan falta de acceso a los servicios de salud, marginación residencial, inadecuada inserción en el mercado laboral, tendencias hacia la segregación ocupacional, limitaciones para recibir una educación de buena calidad y falta de una representación política efectiva en el Estado", entre otros problemas (Figueroa, Altamirano y Sulmont, 1996; Ñopo, Saavedra y Torero, 2004; Torero y otros, 2004, citados en Valdivia, Benavides y Torero, 2007). El Banco Mundial (2014) afirma que las personas y los grupos son excluidos sobre la base de su identidad según el género, la raza, la casta, la orientación sexual, la nacionalidad, el VIH/sida, la etnicidad, la religión y la situación de discapacidad. "La exclusión social basada en esos atributos de grupo puede conducir a una posición social más baja, acompañada a menudo por menores resultados en cuanto a ingreso, aportes de capital humano, acceso al empleo y servicios, y menos voz en la toma de decisiones tanto nacional como local” (Banco Mundial, 2014, pág. 9).

"La exclusión ocurre a través de prácticas y procesos tanto tangibles como intangibles. Aunque resulta más evidente en las diferencias en los resultados 'tangibles', está enraizada en normas y creencias sociales intangibles, lo que a su vez conduce a estereotipos, prejuicios y estigmas. Estas características intangibles son producto de la sociedad y son practicadas tanto por el excluyente como por el excluido" (Banco Mundial, 2014, pág. 11).

"Tomando como referente las características expuestas, la exclusión social se puede analizar y entender como un proceso multidimensional, que tiende a menudo a acumular, combinar y separar, tanto a individuos como a colectivos, de una serie de derechos sociales tales como el trabajo, la educación, la salud, la cultura, la economía y la política, a los que otros colectivos sí tienen acceso y posibilidad de disfrute y que terminan por anular, más tarde o más temprano, el concepto de ciudadanía" (Jiménez Ramírez, 2008, pág. 178).

Sin adentrarse en todo un compendio histórico, se podría decir que "inicialmente el concepto de exclusión social se utilizó en Europa, primero en Francia, Italia y los países nórdicos para hacer referencia a los nuevos problemas sociales y económicos asociados a la globalización, como el empleo precario y el subempleo, la inserción económica, política y cultural de los inmigrantes o la desintegración social producto de diferencias étnicas" (Gacitúa y Davis, 2000, pág. 11). Su origen se nutre en gran parte de las aportaciones teóricas "desarrolladas en épocas anteriores por clásicas figuras de la Sociología tales como Marx, Engels, Durkheim, Tönnies, Bourdieu y Parkin, haciendo especial incidencia en el alienamiento dual de la 'clase social' y en la dinámica 'dentro-fuera'. Sin embargo, las [contribuciones] más recientes del concepto exclusión social se le atribuyen generalmente a René Lenoir (1974), en su obra pionera Les exclus: un Française sur dix" (Jiménez Ramírez, 2008), donde se estimaba que 1 de cada 10 franceses podía considerarse excluido, y se identificaban incluso los grupos sociales en cuestión. 
La influencia de la Unión Europea en la generalización del concepto de exclusión social ha sido remarcada por numerosos investigadores sociales. En efecto, el término apareció por primera vez en 1989 en el Segundo Programa Europeo de Lucha contra la Pobreza la Unión Europea fue la que impulsó el debate sobre la pobreza y las nuevas formas de desigualdad, marginación y vulnerabilidad social. "A finales de los ochenta y principios de los noventa, la Comisión Europea se planteó como objetivo establecer una dimensión social para la política de la Unión Europea, mediante el impulso del debate, la acción y la investigación de la pobreza" (IGOP, 2003, pág. 21).

En el Primer Programa de Lucha Contra la Pobreza (1975-1980) de la Unión Europea se consideraba pobres a los ciudadanos que tenían tan pocos recursos que quedaban excluidos de los niveles de convivencia considerados aceptables en sus países de residencia; es decir, la pobreza se medía en términos estrictamente monetarios (de distribución de la renta o del gasto). Es en el Segundo Programa de Lucha contra la Pobreza (1985-1989) "donde se alude explícitamente a la exclusión social, y aunque enfatiza también la falta de recursos, amplía su contenido a los de tipo social y cultural, es decir, a todos los mecanismos mediante los cuales las familias o grupos de personas puedan sentirse excluidos" (Estivill, 2004, págs. 29-38, citado en Hernández Pedreño, 2008). No obstante, el término exclusión social se fijará recién en 1991 en el programa de la Comunidad Europea para la integración económica y social de los grupos menos favorecidos Pobreza 3, y en las indicaciones del Observatorio de las Políticas Nacionales de Lucha Contra la Exclusión Social (IGOP, 2003, pág. 22).

Esto evidencia que la exclusión social es un fenómeno propio de las sociedades modernas que supera los conceptos de pobreza, marginación y desigualdad: según esta concepción, un grupo de personas en situación de pobreza siempre se considera excluido, pero no todo grupo excluido socialmente es pobre.

\section{Medición alternativa}

El concepto de exclusión social puede ser una herramienta de investigación eficaz a los efectos de comparar los diferentes tipos de eficacia de la política social como principal mecanismo para prevenir la aparición y la extensión del fenómeno. La aplicación del concepto a los discursos políticos y científicos ofrece una oportunidad para hacer comparaciones internacionales que permitan hallar manifestaciones comunes y diferentes de la exclusión en los países en que se aplican enfoques alternativos al formular políticas sociales. Sin embargo, un requisito previo para hacer comparaciones interculturales es usar herramientas equivalentes para recopilar los datos. Hacer tal comparación implica que la estructura del fenómeno que se estudia es similar en diferentes sociedades (Loktieva, 2016, págs. 148-149).

En la literatura existe consenso general en que la exclusión social tiene las siguientes características: es multidimensional; es dinámica; ocurre en un tiempo y lugar determinados; es relativa (o comparativa); es estructural; es relacional y tiene que ver con los procesos sociales. Sobre la base de estas características y dada la importancia que el fenómeno tiene en el planteamiento de políticas públicas, en las últimas dos décadas los investigadores han comenzado a poner en práctica el concepto de exclusión social de forma cuantitativa. Como dicen Good Gingrich y Lightman (2015), los primeros intentos por hacer esto se basaban en gran medida en variables conocidas y bastante utilizadas, como los ingresos personales o familiares, y el consumo inferior a un umbral de pobreza. En los estudios más recientes se utiliza una combinación de indicadores materiales y sociales, con lo que se hace hincapié en la naturaleza multidimensional del fenómeno. Los citados autores proponen un índice de exclusión social relativo al Canadá que tiene características multidimensionales de privación material y aislamiento social, y ratifican el hecho de que la exclusión social recae con mayor énfasis en la población migrante y los grupos étnicos minoritarios y de piel más oscura. 
En una investigación sobre Ucrania y varios países europeos, Loktieva (2016) sigue esta línea multidimensional y llega a la conclusión de que los componentes distributivos y relacionales de la exclusión social son similares en países que tienen niveles socioeconómicos y modelos de desarrollo y bienestar social distintos.

Muchos de los elementos que Alkire y Foster (2007) utilizan en el cálculo de la pobreza multidimensional se aplican también a la exclusión social, dado que esta tiene las características que se han mencionado y que también se define por la acumulación de déficits (privaciones) que se interrelacionan y retroalimentan entre sí. En este sentido, Domínguez y Núñez (2013) también han desarrollado un índice sintético de la exclusión social en que se utiliza un conjunto de indicadores cuantitativos y cualitativos provenientes de la Encuesta de Condiciones de Vida de España. En el índice los autores emplean el indicador de exclusión social que ellos propusieron en 2009, a partir de conjuntos difusos.

En la presente investigación se propone utilizar el grado de exclusión social (ges) como medida alternativa y como variación del índice de pobreza multidimensional (IPM) que utiliza el Departamento Administrativo Nacional de Estadística (DANE) de Colombia, a partir de privaciones de los hogares en 15 variables y 5 dimensiones, según un umbral normativo (zj) establecido para cada variable.

La privación se establece como sigue:

$$
\begin{aligned}
& X=\left[\begin{array}{ccc}
x_{11} & \cdots & x_{1 j} \\
\vdots & \ddots & \vdots \\
x_{N 1} & \cdots & x_{N j}
\end{array}\right] ; \quad \bar{X}=\left[\begin{array}{ccc}
\bar{x}_{11} & \cdots & \bar{x}_{1 j} \\
\vdots & \ddots & \vdots \\
\bar{x}_{N 1} & \cdots & \bar{x}_{N j}
\end{array}\right] ; \quad \bar{x}_{i j}\left\{\begin{array}{l}
1 \text { si } x_{i j}<z_{j} \\
0 \text { si } N o
\end{array}\right. \\
& Z=\left[\begin{array}{lll}
z_{1} & z_{2} \ldots & z_{j}
\end{array}\right] ; \quad W=\left[\begin{array}{lll}
w_{1} & w_{2} & \ldots \\
w_{j}
\end{array}\right]
\end{aligned}
$$

$C=\left(c_{1}, c_{2}, \ldots c_{N}\right)$, donde $c_{i}(i=1,2,3, \ldots N)$, pero $C=\bar{X} . W$ Vector de privaciones ponderadas donde:

$x_{i j}=$ Características del hogar $i$ en la dimensión $j$

$\bar{x}_{i j}=$ Privación del hogar $i$ en la dimensión $j$

$z_{j}=$ Umbral en la dimensión $j$

$w_{j}=$ Peso asignado a la dimensión $j$

$c_{i} \quad=$ Privación ponderada del hogar $i$

$\mathrm{N}=$ Total de hogares de la muestra

$\mathrm{J}=$ Total de dimensiones o variables

El ponderador $w_{j}\left(\sum_{j}^{J} w_{j}=1\right)$ puede construirse a discreción de las autoridades estadísticas nacionales, como sucede generalmente. En algunos países se asignan ponderaciones iguales a las dimensiones y a las variables de cada dimensión, pero, debido a que las dimensiones tienen diferentes números de variables, la ponderación de cada grupo de variables queda diferente. Otras formas de calcular las ponderaciones son las siguientes:

Asignar un peso igual a las variables:

$$
w_{j}=\frac{1}{J}
$$

Asignar la ponderación según el peso relativo de las variables:

$$
w_{j}=\frac{f_{j}}{F} \text {, donde } f_{j}=\frac{1}{N} \sum_{i=1}^{N} \bar{x}_{i j} \text { y } F=\sum_{j=1}^{J} f_{j}
$$


En esta investigación, para estimar las ponderaciones $\left(w_{j}\right)$ se considerará la relación funcional inversa entre el sistema de ponderaciones y las frecuencias correspondientes a las no privaciones de los hogares $\left(g_{j}=1-f_{j}\right)$ propuesta por Dagum, Gambassi y Lemmi (1992) y ajustada por Domínguez y Núñez (2013). En este caso:

$$
w_{j}=\frac{v_{j}}{V} ; v_{j}=\ln \left(1 / g_{j}\right) \text { donde } g_{j}=\frac{1}{N} \sum_{i=1}^{N}\left(1-\bar{x}_{i j}\right) \text { y } V=\sum_{j=1}^{J} v_{j}
$$

De lo anterior obtenemos la siguiente igualdad:

$$
\operatorname{ges}_{i}=c_{i}
$$

\section{Resultados}

\section{La base de datos}

Para aplicar las metodologías detalladas anteriormente se utilizaron los datos de 121.802 hogares de la Encuesta Nacional de Calidad de Vida (ECV) de Colombia correspondiente al período 2012-2017, con representación estadística a nivel nacional y según los dominios urbano y rural. Esta ECV es una investigación que el DANE lleva a cabo con el objeto de recolectar información sobre diferentes aspectos y dimensiones del bienestar de los hogares, a saber, el acceso a bienes y servicios públicos, privados o comunales, a la salud, a la educación y al cuidado de niños y niñas menores de 5 años, entre otros. Considerar estos aspectos permite analizar posteriormente los factores que explican los diferentes niveles de vida que hay en la sociedad ${ }^{1}$.

\section{El factor de etnicidad (fet) en Colombia}

De conformidad con los datos disponibles y la metodología propuesta, es posible obtener el factor de etnicidad de Colombia vinculando las variables correspondientes al color de la piel, la autoadscripción a un grupo étnico y la inmigración. Los resultados se muestran en el gráfico 1.

Los datos dan cuenta de que Colombia es un país muy étnico, ya que en el período analizado el factor de etnicidad es aproximadamente 0,46 en una escala de 0 a 1. Los valores forman una onda sinusoidal que exhibe un repunte importante en 2015 y 2016 debido en parte al leve mejoramiento económico del país.

Respecto a cada una de las variables que integran el factor de etnicidad, en el gráfico 2 se observa que el color de piel y la autoadscripción a un grupo étnico también exhiben un comportamiento sinusoidal muy disimulado que se corresponde con el del factor en su conjunto. Así mismo, se observa un ascenso generalizado de la inmigración, con un repunte pronunciado en 2017 debido en buena parte a la llegada masiva de personas de la República Bolivariana de Venezuela.

\footnotetext{
1 La información se obtiene del sitio web del DANE a nivel de microdatos (véase [en línea] www.dane.gov.co).
} 
Gráfico 1

Colombia: factor de etnicidad, 2012-2017

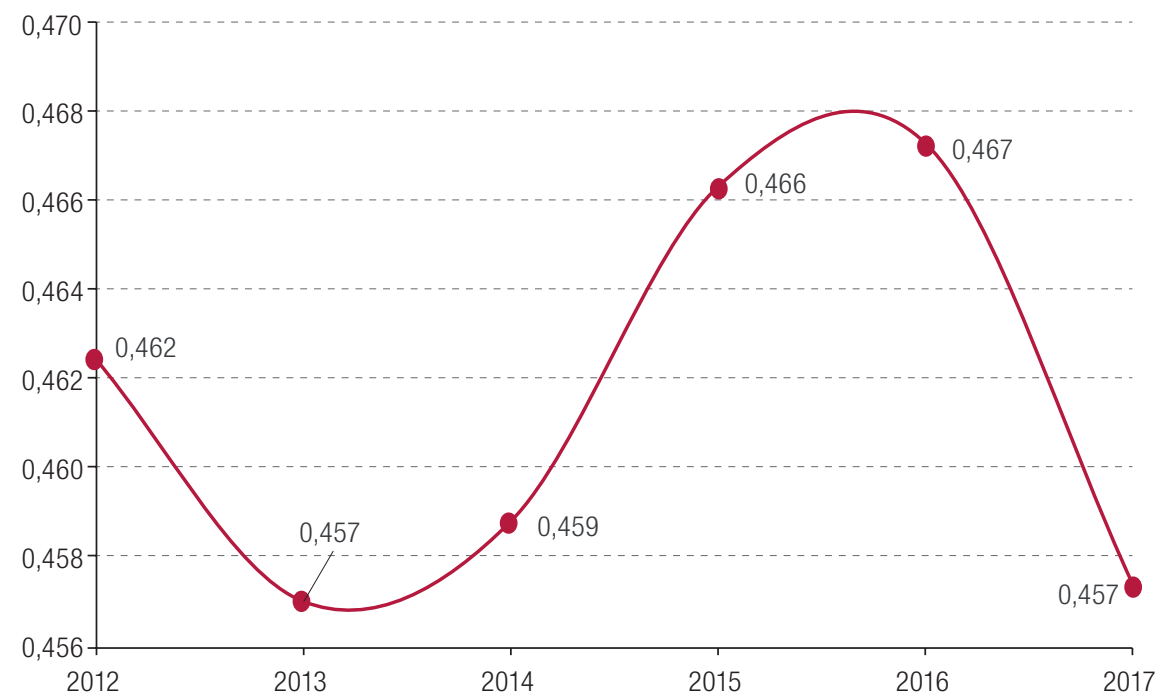

Fuente: Elaboración propia.

Gráfico 2

Colombia: componentes de la etnicidad, 2012-2017

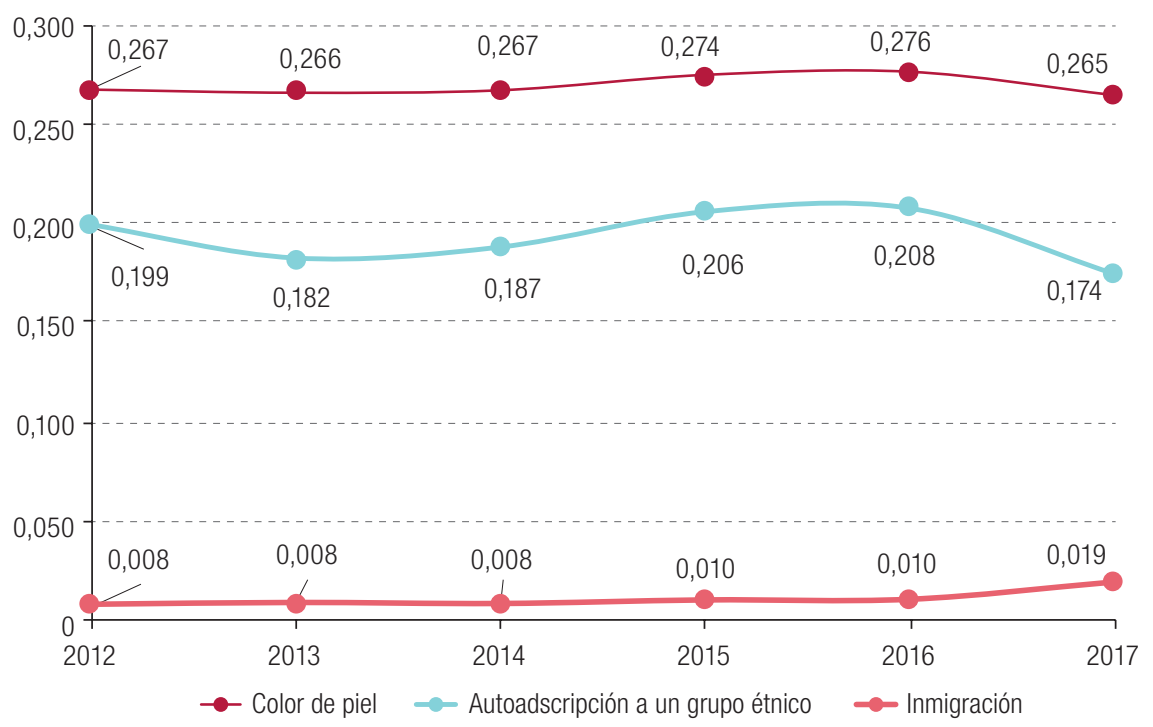

Fuente: Elaboración propia.

En el cuadro 2 se pueden observar de forma más detallada los componentes de la etnicidad en Colombia. 


\section{Cuadro 2}

Colombia: factor de etnicidad, por grupo de interés, 2012-2017

\begin{tabular}{lllllllll}
\hline Variable & Criterio & 2012 & 2013 & 2014 & 2015 & 2016 & 2017 & Total \\
\hline Color de piel $(c p)$ & $<=0,45$ & 0,418 & 0,407 & 0,407 & 0,409 & 0,409 & 0,406 & 0,410 \\
\cline { 2 - 8 } & $>0,45$ & 0,773 & 0,772 & 0,772 & 0,772 & 0,772 & 0,773 & 0,772 \\
\hline \multirow{2}{*}{$\begin{array}{l}\text { Autoadscripción a un } \\
\text { grupo étnico (age) }\end{array}$} & No & 0,389 & 0,389 & 0,389 & 0,389 & 0,389 & 0,392 & 0,389 \\
\cline { 2 - 8 } & Sí & 0,760 & 0,764 & 0,763 & 0,764 & 0,765 & 0,767 & 0,764 \\
\cline { 2 - 8 } & Gitanos & 0,577 & 0,612 & 0,577 & 0,625 & 0,577 & 0,577 & 0,589 \\
\cline { 2 - 8 } & Afrodescendientes & 0,773 & 0,772 & 0,772 & 0,772 & 0,772 & 0,773 & 0,772 \\
\cline { 2 - 8 } & Indígenas & 0,739 & 0,739 & 0,738 & 0,739 & 0,739 & 0,740 & 0,739 \\
\hline Inmigración (im) & No & 0,460 & 0,455 & 0,457 & 0,464 & 0,464 & 0,452 & 0,459 \\
\cline { 2 - 8 } & Sí & 0,730 & 0,729 & 0,745 & 0,747 & 0,739 & 0,724 & 0,735 \\
\hline \multirow{2}{*}{ Género } & Hombre & 0,462 & 0,456 & 0,459 & 0,463 & 0,464 & 0,455 & 0,460 \\
\cline { 2 - 8 } & Mujer & 0,464 & 0,459 & 0,459 & 0,473 & 0,474 & 0,461 & 0,465 \\
\hline \multirow{2}{*}{ Zona } & Rural & 0,468 & 0,462 & 0,464 & 0,458 & 0,462 & 0,459 & 0,462 \\
\cline { 2 - 8 } & Urbana & 0,459 & 0,454 & 0,455 & 0,471 & 0,471 & 0,457 & 0,462 \\
\hline Diferencia & Étnica & 0,371 & 0,375 & 0,375 & 0,375 & 0,375 & 0,374 & 0,374 \\
\cline { 2 - 7 } & De género & 0,002 & 0,003 & 0,000 & 0,010 & 0,010 & 0,006 & 0,005 \\
\cline { 2 - 8 } & Por zona & 0,009 & 0,008 & 0,009 & $-0,013$ & $-0,009$ & 0,002 & 0,0005 \\
\hline
\end{tabular}

Fuente: Elaboración propia.

Los datos indican que, tal como sugiere la teoría, la etnicidad es mayor en el caso de los tonos de piel más oscuros ( $c p>0,45)$, de quienes se autoadscriben a algún grupo étnico, de los inmigrantes y de los hogares rurales. Entre los grupos étnicos, los afrodescendientes son los que tienen el factor de etnicidad más elevado, seguidos de los indígenas y los gitanos, en ese orden. Los mestizos o los que no se autoidentifican con ningún grupo étnico, por otra parte, son los que presentan la menor etnicidad.

\section{El grado de exclusión social (ges) en Colombia}

De conformidad con la metodología propuesta, el indicador de exclusión social de Colombia alcanza un valor promedio de un 55\% de privación en los hogares. El indicador exhibió un descenso importante en 2015, cuando hubo una mejora general de las condiciones de vida del país, pero volvió a crecer en los años subsiguientes (véase el gráfico 3).

\section{Gráfico 3}

Colombia: grado de exclusión social, 2012-2017

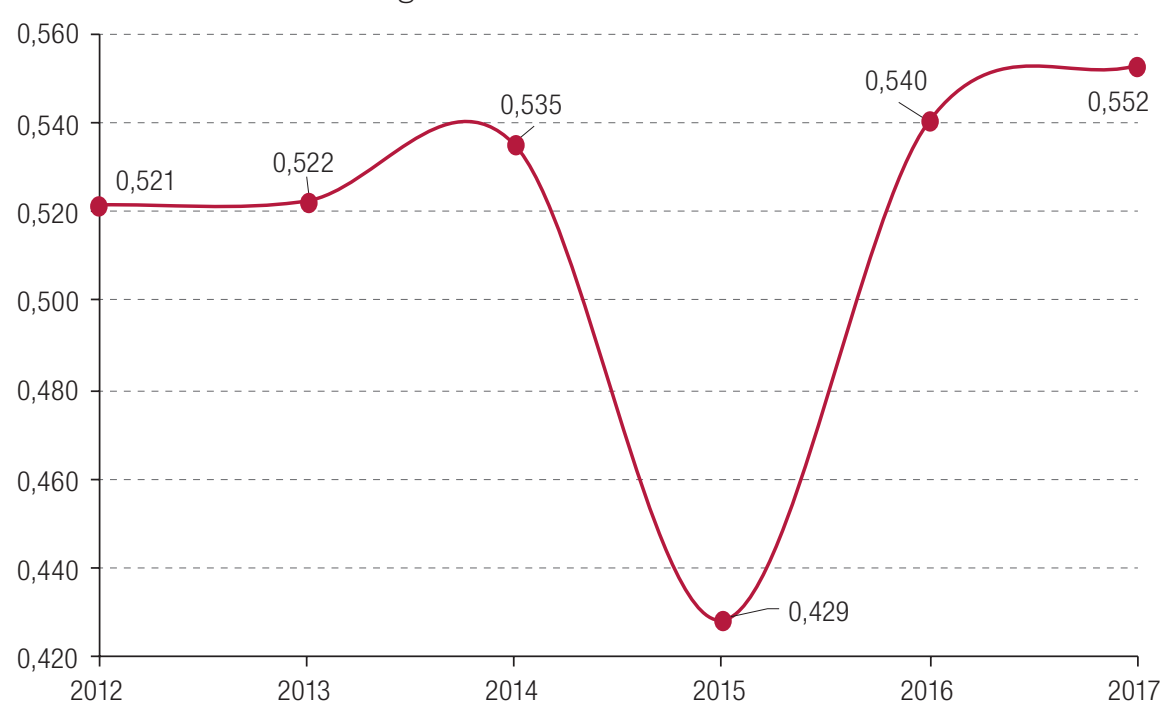

Fuente: Elaboración propia. 
En el cuadro 3 se muestra el comportamiento del indicador durante el período de análisis en relación con algunos grupos de interés. Se observa, por ejemplo, que la exclusión social es mayor en la población de piel más oscura $(c p>0,45)$, los grupos étnicos, los hombres y la población rural.

\section{Cuadro 3}

Colombia: exclusión social, por grupo de interés, 2012-2017

\begin{tabular}{lllllllll}
\hline Variable & Criterio & 2012 & 2013 & 2014 & 2015 & 2016 & 2017 & Total \\
\hline Color de piel (cp) & $<=0,45$ & 0,519 & 0,521 & 0,533 & 0,428 & 0,539 & 0,549 & 0,512 \\
\cline { 2 - 8 } & $>0,45$ & 0,537 & 0,530 & 0,548 & 0,431 & 0,544 & 0,573 & 0,521 \\
\hline $\begin{array}{l}\text { Autoadscripción a un } \\
\text { grupo étnico (age) }\end{array}$ & No & 0,514 & 0,517 & 0,529 & 0,422 & 0,535 & 0,548 & 0,508 \\
\cline { 2 - 8 } & Sí & 0,551 & 0,545 & 0,559 & 0,453 & 0,558 & 0,576 & 0,536 \\
\cline { 2 - 8 } & Gitanos & 0,476 & 0,480 & 0,464 & 0,497 & 0,462 & 0,545 & 0,479 \\
\cline { 2 - 8 } & Afrodescendientes & 0,537 & 0,530 & 0,548 & 0,431 & 0,544 & 0,573 & 0,521 \\
\cline { 2 - 8 } & Indígenas & 0,577 & 0,594 & 0,594 & 0,526 & 0,608 & 0,587 & 0,579 \\
\hline Inmigración (im) & No & 0,522 & 0,523 & 0,536 & 0,429 & 0,540 & 0,553 & 0,514 \\
\cline { 2 - 8 } & Sí & 0,419 & 0,467 & 0,475 & 0,371 & 0,510 & 0,535 & 0,466 \\
\hline Género & Hombre & 0,526 & 0,527 & 0,540 & 0,431 & 0,544 & 0,549 & 0,516 \\
\cline { 2 - 8 } & Mujer & 0,513 & 0,514 & 0,527 & 0,424 & 0,534 & 0,557 & 0,508 \\
\hline Zona & Rural & 0,590 & 0,589 & 0,602 & 0,529 & 0,601 & 0,592 & 0,583 \\
\cline { 2 - 8 } & Urbana & 0,478 & 0,481 & 0,491 & 0,368 & 0,503 & 0,532 & 0,471 \\
\hline Diferencia & Étnica & 0,037 & 0,028 & 0,030 & 0,031 & 0,023 & 0,028 & 0,028 \\
\cline { 2 - 8 } & De género & 0,013 & 0,013 & 0,013 & 0,008 & 0,010 & $-0,007$ & 0,009 \\
\cline { 2 - 7 } & Por zona & 0,112 & 0,108 & 0,111 & 0,161 & 0,098 & 0,060 & 0,112 \\
\hline
\end{tabular}

Fuente: Elaboración propia.

En términos generales, el indicador de exclusión social presenta una tendencia de crecimiento leve en el país. Además, en los hogares colombianos se observa un deterioro paulatino de las condiciones de vida que es más pronunciado en las zonas rurales y en los hogares en que la etnicidad es mayor, bien por el color de piel o por la pertenencia a grupos étnicos.

\section{La relación entre el factor de etnicidad y al grado de exclusión social en Colombia en el período 2012-2017}

En Colombia, los procesos más intensos de exclusión social definitivamente se observan en los grupos o sectores sociales cuyo factor de etnicidad es mayor. Esto no quiere decir que en los países no haya otras líneas de exclusión, como el género, la edad o la religión. Lo que sí parece querer decir es que las diferencias étnicas, raciales y de nacionalidad se encuentran entre los factores más evidentes de exclusión social.

Los resultados de la presente investigación dan cuenta de una relación directa e importante entre el factor de etnicidad (fet) y el grado de exclusión social (ges). Esa relación se obtiene a partir de la regresión simple de mínimos cuadrados ordinarios (MCO) que se indica a continuación:

$$
\operatorname{ges}_{i}=\beta_{0}+\beta_{1} f t_{i}+\mu_{i}
$$

donde $\beta_{0}$ representa el coeficiente del intercepto, $\beta_{1}$ es la medida en que una variación de la etnicidad afecta el grado de exclusión social y $\mu_{i}$ representa el error.

Los resultados de la regresión anterior se muestran en el gráfico 4. 


\section{Gráfico 4}

Colombia: relación entre el grado de exclusión social y el factor de etnicidad, 2012-2017

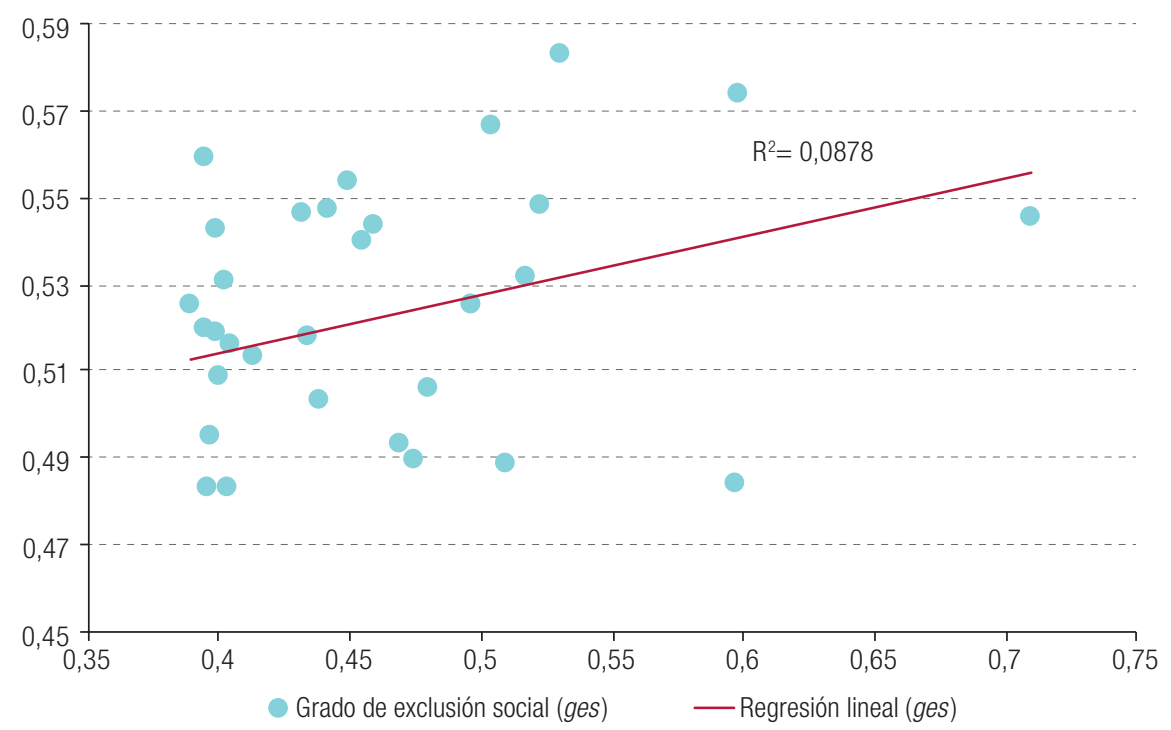

Fuente: Elaboración propia.

Nota: La relación entre el grado de exclusión social (eje vertical) y el factor de etnicidad (eje horizontal) se obtuvo a partir de una regresión simple de mínimos cuadrados ordinarios (MCO).

Para analizar esta relación de manera más detallada se recurre a una regresión múltiple de la exclusión social y el factor de etnicidad, controlando por características de los jefes de hogar. Esto permite determinar si un incremento de la etnicidad en su conjunto o de alguno de sus componentes aumenta el grado de exclusión social en los hogares objeto de estudio. La información obtenida a partir de la ECV se organiza en cortes transversales correspondientes a los años 2012 a 2017, y se establece el siguiente modelo:

$$
Y_{i}=\beta_{0}+\beta_{1} X_{i}+\beta_{2} Z_{i}+\beta_{3} T_{j}+V_{i}
$$

donde $Y_{i}$ es la variable que mide la exclusión social (ges), $X_{i}$ es la variable que captura la etnicidad (fet) o cada uno de sus componentes (cp, age, $i m$ ), $Z_{i}$ es un vector de variables de control, $T_{j}$ es un conjunto de variables dicotómicas de cada uno de los años analizados, y $V_{i}$ representa el error en el modelo.

Esta ecuación se estima por mínimos cuadrados ordinarios (MCO) para obtener el grado de exclusión social en relación con el factor de etnicidad y con cada una de las variables que lo componen. Las variables de control se refieren a los datos personales y sociodemográficos de los jefes de hogar (educación, género, ingresos y zona de residencia). La idea de introducir variables dicotómicas correspondientes a los años es que reflejan los cambios de la exclusión social condicionada a la etnicidad ceteris paribus el paso del tiempo y las otras variables de control.

De conformidad con los resultados, la relación directa entre la etnicidad y la exclusión social en Colombia se conserva de manera significativa con un 95\% de confianza: cuando la etnicidad se incrementa 1 punto porcentual, la exclusión social aumenta 7 puntos porcentuales (véase el cuadro 4). 
Cuadro 4

Colombia: modelo de regresión lineal correspondiente al grado de exclusión social, 2012-2017

\begin{tabular}{|c|c|c|c|c|}
\hline \multirow{2}{*}{ Variables } & \multicolumn{4}{|c|}{ Grado de exclusión social } \\
\hline & (1) & (2) & (3) & (4) \\
\hline \multirow[t]{2}{*}{ Factor de etnicidad } & $0,0711^{\star \star \star}$ & & & \\
\hline & $(0,00212)$ & & & \\
\hline \multirow[t]{2}{*}{ Educación } & $-0,0188^{\star \star \star}$ & $-0,0188^{\star \star *}$ & $-0,0187^{\star \star \star}$ & $-0,0187^{\star \star *}$ \\
\hline & $(7,85 e-05)$ & $(7,85 e-05)$ & $(7,85 e-05)$ & $(7,89 e-05)$ \\
\hline \multirow[t]{2}{*}{ Ingreso per cápita } & $-7,80 \mathrm{e}-09^{\star \star \star}$ & $-7,80 \mathrm{e}-09^{\star * *}$ & $-7,73 e-09^{* \star *}$ & $-8,07 \mathrm{e}-09^{* * *}$ \\
\hline & $(2,51 \mathrm{e}-10)$ & $(2,51 \mathrm{e}-10)$ & $(2,51 \mathrm{e}-10)$ & $(2,52 \mathrm{e}-10)$ \\
\hline \multirow[t]{2}{*}{ Hombre } & 0,000789 & 0,000882 & 0,000829 & 0,000358 \\
\hline & $(0,000673)$ & $(0,000674)$ & $(0,000673)$ & $(0,000676)$ \\
\hline \multirow[t]{2}{*}{ Rural } & $0,0477^{\star \star *}$ & $0,0481^{* \star *}$ & $0,0475^{\star \star \star}$ & $0,0479^{* * *}$ \\
\hline & $(0,000712)$ & $(0,000712)$ & $(0,000712)$ & $(0,000715)$ \\
\hline \multirow[t]{2}{*}{2012} & $-0,0569^{\star \star \star}$ & $-0,0567^{\star \star \star}$ & $-0,0572^{\star \star \star}$ & $-0,0564^{\star \star \star}$ \\
\hline & $(0,00124)$ & $(0,00125)$ & $(0,00124)$ & $(0,00125)$ \\
\hline \multirow[t]{2}{*}{2013} & $-0,0525^{\star \star \star}$ & $-0,0526^{\star \star \star}$ & $-0,0527^{\star \star \star}$ & $-0,0523^{\star \star \star}$ \\
\hline & $(0,00124)$ & $(0,00124)$ & $(0,00124)$ & $(0,00125)$ \\
\hline \multirow[t]{2}{*}{2014} & $-0,0416^{\star \star \star}$ & $-0,0417^{\star \star \star}$ & $-0,0418^{\star \star \star}$ & $-0,0413^{\star \star \star}$ \\
\hline & $(0,00126)$ & $(0,00126)$ & $(0,00126)$ & $(0,00126)$ \\
\hline \multirow[t]{2}{*}{2015} & $-0,142^{\star \star \star}$ & $-0,142^{\star \star \star}$ & $-0,142^{\star \star \star}$ & $-0,141^{\star \star \star}$ \\
\hline & $(0,00122)$ & $(0,00123)$ & $(0,00122)$ & $(0,00123)$ \\
\hline \multirow[t]{2}{*}{2016} & $-0,0273^{* \star \star}$ & $-0,0273^{\star \star \star}$ & $-0,0274^{\star \star \star}$ & $-0,0264^{\star * \star}$ \\
\hline & $(0,00122)$ & $(0,00122)$ & $(0,00122)$ & $(0,00123)$ \\
\hline \multirow[t]{2}{*}{ Color de piel $(c p)$} & & $0,0640^{\star \star \star}$ & & \\
\hline & & $(0,00215)$ & & \\
\hline \multirow[t]{2}{*}{ Autoadscripción a un grupo étnico (age) } & & & $0,0269^{\star \star *}$ & \\
\hline & & & $(0,000809)$ & \\
\hline \multirow[t]{2}{*}{ Inmigración (im) } & & & & $0,0199^{\star \star \star}$ \\
\hline & & & & $(0,00326)$ \\
\hline \multirow[t]{2}{*}{ Constante $\left(\beta_{o}\right)$} & $0,676^{\star \star \star}$ & $0,692^{\star \star *}$ & $0,704^{\star \star \star}$ & $0,709^{\star \star \star}$ \\
\hline & $(0,00162)$ & $(0,00142)$ & $(0,00131)$ & $(0,00131)$ \\
\hline Observaciones & 121419 & 121419 & 121419 & 121419 \\
\hline$R^{2}$ & $48,5 \%$ & $48,4 \%$ & $48,5 \%$ & $48,0 \%$ \\
\hline
\end{tabular}

Fuente: Elaboración propia.

Nota: Se estimó por mínimos cuadrados ordinarios (MCO). Los errores estándares se indican entre paréntesis. ${ }^{\star \star \star} p<0,01$, ${ }^{* *} p<0,05,{ }^{*} p<0,1$

En esta misma regresión se observa que la relación directa entre exclusión social y etnicidad se mantiene cuando se observan cada uno de los componentes de esta última: el hecho de tener un tono de piel más oscuro, autoadscribirse a un grupo étnico o pertenecer a la categoría de inmigrante aumenta el grado de exclusión social en Colombia. Además, el modelo ratifica que tener un mayor nivel de educación o de ingreso contrarresta la posibilidad de ser objeto de exclusión social o facilita la salida de esa situación. Otras variables de control, como residir en las zonas rurales del país, aumentan la exclusión social de las personas. Ser hombre o mujer, por su parte, no incide de forma significativa en el nivel de exclusión social.

Cuando se analiza la regresión en cada año del período en estudio, se observa que los resultados son coherentes y que hay un margen de variación de entre 6 y 9,4 puntos porcentuales por cada punto de variación de la etnicidad. Los componentes de la etnicidad también exhiben unos márgenes reducidos cada año respecto al período global. Así mismo, el coeficiente de determinación $\left(R^{2}\right)$ se mantiene alrededor del 48\% (véase el cuadro 5). 


\section{Cuadro 5}

Colombia: regresión del grado de exclusión social por año, 2012-2017

\begin{tabular}{|c|c|c|c|c|c|c|}
\hline \multirow{2}{*}{ Variables } & \multicolumn{6}{|c|}{ Grado de exclusión social } \\
\hline & 2012 & 2013 & 2014 & 2015 & 2016 & 2017 \\
\hline \multirow[t]{2}{*}{ Factor de etnicidad } & $0,0776^{\star \star \star}$ & $0,0685^{\star \star \star}$ & $0,0668^{\star \star \star}$ & $0,0942^{\star \star \star}$ & $0,0596^{\star \star \star}$ & $0,0595^{\star \star \star}$ \\
\hline & $(0,00443)$ & $(0,00443)$ & $(0,00446)$ & $(0,00686)$ & $(0,00387)$ & $(0,00506)$ \\
\hline$R^{2}$ & $48,7 \%$ & $48,0 \%$ & $50,22 \%$ & $45,5 \%$ & $47,2 \%$ & $43,2 \%$ \\
\hline \multirow[t]{2}{*}{ Color de piel } & $0,0769^{\star \star \star}$ & $0,0611^{\star \star \star}$ & $0,0641^{\star \star \star}$ & $0,0771^{\star \star \star}$ & $0,0547^{\star \star \star}$ & $0,0533^{\star \star \star}$ \\
\hline & $(0,00459)$ & $(0,00445)$ & $(0,00453)$ & $(0,00697)$ & $(0,00390)$ & $(0,00509)$ \\
\hline$R^{2}$ & $48,6 \%$ & $47,9 \%$ & $50,1 \%$ & $45,4 \%$ & $47,1 \%$ & $43,1 \%$ \\
\hline \multirow[t]{2}{*}{ Grupo étnico } & $0,0300^{\star \star \star}$ & $0,0263^{\star \star \star}$ & $0,0255^{\star \star \star}$ & $0,0350^{\star \star \star}$ & $0,0224^{\star \star \star}$ & $0,0213^{\star \star \star}$ \\
\hline & $(0,00167)$ & $(0,00169)$ & $(0,00170)$ & $(0,00262)$ & $(0,00148)$ & $(0,00197)$ \\
\hline$R^{2}$ & $48,7 \%$ & $48,0 \%$ & $50,2 \%$ & $45,5 \%$ & $47,2 \%$ & $43,1 \%$ \\
\hline \multirow[t]{2}{*}{ Inmigración } & $-0,0107$ & $0,0140^{*}$ & $0,0146^{*}$ & $0,0481^{\star \star \star}$ & $0,0161^{\star \star \star}$ & $0,0255^{\star \star \star}$ \\
\hline & $(0,00779)$ & $(0,00717)$ & $(0,00752)$ & $(0,0108)$ & $(0,00603)$ & $(0,00553)$ \\
\hline$R^{2}$ & $47,9 \%$ & $47,4 \%$ & $49,6 \%$ & $45,1 \%$ & $46,6 \%$ & $42,7 \%$ \\
\hline Observaciones & 21171 & 21329 & 20004 & 22829 & 23091 & 12995 \\
\hline
\end{tabular}

Fuente: Elaboración propia.

Nota: Se estimó por mínimos cuadrados ordinarios (MCO). Los errores estándares se indican entre paréntesis. ${ }^{\star \star \star} \mathrm{p}<0,01$, ${ }^{\star *} p<0,05,{ }^{*} p<0,1$.

Además, al establecer una ecuación de Mincer en que participa la etnicidad de las personas encontramos que, cuando esta aumenta, se reduce el nivel de ingreso esperado, al contrario de lo que sucede con los años de educación (véase el cuadro 6).

\section{Cuadro 6}

Colombia: ecuación de Mincer respecto de la etnicidad, 2012-2016

\begin{tabular}{|c|c|c|c|c|}
\hline \multirow{2}{*}{ Variables } & \multicolumn{4}{|c|}{ Logaritmo natural del ingreso per cápita } \\
\hline & (1) & (2) & (3) & (4) \\
\hline \multirow[t]{2}{*}{ Fet } & $-0,355^{\star \star \star}$ & & & \\
\hline & $(0,0211)$ & & & \\
\hline \multirow[t]{2}{*}{ Educación } & $0,122^{\star \star \star}$ & $0,122^{\star \star \star}$ & $0,122^{\star \star \star}$ & $0,122^{\star \star \star}$ \\
\hline & $(0,000910)$ & $(0,000910)$ & $(0,000910)$ & $(0,000912)$ \\
\hline \multirow[t]{2}{*}{ Exper Pot (experiencia potencial) } & $0,0246^{\star \star *}$ & $0,0247^{\star \star \star}$ & $0,0246^{\star \star \star}$ & $0,0249^{\star \star \star}$ \\
\hline & $(0,000672)$ & $(0,000672)$ & $(0,000672)$ & $(0,000673)$ \\
\hline \multirow[t]{2}{*}{ Exper Pot ${ }^{2}$} & $-0,000155^{\star \star \star}$ & $-0,000155^{\star \star \star}$ & $-0,000155^{\star \star \star}$ & $-0,000155^{\star \star \star}$ \\
\hline & $(8,44 \mathrm{e}-06)$ & $(8,44 \mathrm{e}-06)$ & $(8,44 \mathrm{e}-06)$ & $(8,45 e-06)$ \\
\hline \multirow[t]{2}{*}{ Hombre } & $0,251^{\star \star \star}$ & $0,250^{\star \star \star}$ & $0,250^{\star \star \star}$ & $0,253^{\star \star \star}$ \\
\hline & $(0,00673)$ & $(0,00673)$ & $(0,00672)$ & $(0,00673)$ \\
\hline \multirow[t]{2}{*}{ Urbano } & $0,313^{* \star \star}$ & $0,315^{\text {***}}$ & $0,312^{* \star \star}$ & $0,313^{\star * *}$ \\
\hline & $(0,00711)$ & $(0,00711)$ & $(0,00710)$ & $(0,00711)$ \\
\hline \multirow[t]{2}{*}{2012} & $-0,398^{\star \star \star}$ & $-0,399^{\star \star \star}$ & $-0,396^{\star \star \star}$ & $-0,399^{\star \star \star}$ \\
\hline & $(0,0124)$ & $(0,0124)$ & $(0,0124)$ & $(0,0125)$ \\
\hline \multirow[t]{2}{*}{2013} & $-0,330^{\star \star \star}$ & $-0,329^{\star \star \star}$ & $-0,329^{\star \star \star}$ & $-0,329^{\star \star \star}$ \\
\hline & $(0,0124)$ & $(0,0124)$ & $(0,0124)$ & $(0,0124)$ \\
\hline \multirow[t]{2}{*}{2014} & $-0,279^{\star \star \star}$ & $-0,278^{\star \star *}$ & $-0,277^{\star \star \star}$ & $-0,278^{\star \star *}$ \\
\hline & $(0,0125)$ & $(0,0125)$ & $(0,0125)$ & $(0,0126)$ \\
\hline \multirow[t]{2}{*}{2015} & $-0,0863^{\star \star \star}$ & $-0,0867^{\star \star \star}$ & $-0,0850^{\star \star \star}$ & $-0,0888^{* \star \star}$ \\
\hline & $(0,0122)$ & $(0,0122)$ & $(0,0122)$ & $(0,0122)$ \\
\hline \multirow[t]{2}{*}{2016} & $-0,0604^{\star \star *}$ & $-0,0608^{\star \star \star}$ & $-0,0591^{\star \star \star}$ & $-0,0633^{\star \star *}$ \\
\hline & $(0,0122)$ & $(0,0122)$ & $(0,0122)$ & $(0,0122)$ \\
\hline \multirow[t]{2}{*}{ Color de piel $(c p)$} & & $-0,286^{\star \star \star}$ & & \\
\hline & & $(0,0214)$ & & \\
\hline
\end{tabular}


Cuadro 6 (conclusión)

\begin{tabular}{|c|c|c|c|c|}
\hline \multirow{2}{*}{ Variables } & \multicolumn{4}{|c|}{ Logaritmo natural del ingreso per cápita } \\
\hline & $(1)$ & $(2)$ & (3) & (4) \\
\hline \multirow[t]{2}{*}{ Autoadscripción a un grupo étnico (age) } & & & $-0,148^{\star \star \star}$ & \\
\hline & & & $(0,00806)$ & \\
\hline \multirow[t]{2}{*}{ Inmigración (im) } & & & & $0,0967^{\star \star \star}$ \\
\hline & & & & $(0,0326)$ \\
\hline \multirow[t]{2}{*}{ Constante $\left(\beta_{o}\right)$} & $11,12^{\star \star \star}$ & $11,03^{\star \star \star}$ & $10,99^{\star \star \star}$ & $10,95^{\text {***}}$ \\
\hline & $(0,0220)$ & $(0,0204)$ & $(0,0195)$ & $(0,0194)$ \\
\hline Observaciones & 120295 & 120295 & 120295 & 120295 \\
\hline$R^{2}$ & $21,4 \%$ & $21,3 \%$ & $21,4 \%$ & $21,2 \%$ \\
\hline
\end{tabular}

Fuente: Elaboración propia.

Nota: Se estimó por mínimos cuadrados ordinarios (MCO). Los errores estándares se indican entre paréntesis. ${ }^{* \star *} \mathrm{p}<0,01$, ${ }^{\star *} p<0,05,{ }^{*} p<0,1$

Una vez más se observa que cada uno de los elementos de la etnicidad va en la misma dirección respecto del ingreso de las personas: el aumento de esos elementos reduce el ingreso esperado. No obstante, algunas variables de control, como ser hombre o residir en las zonas urbanas del país, contrarrestan esta tendencia.

\section{Conclusiones}

La etnicidad es una categoría que se construye socialmente, que tiene fuertes implicaciones económicas y que, a su vez, alberga categorías que permiten diferenciar entre grupos poblacionales en un contexto y un tiempo determinados. La raza, la etnia y la inmigración son componentes esenciales de la etnicidad, y juntas representan los mayores elementos de discriminación y exclusión social inspirada en una supuesta superioridad y legitimidad de los unos respecto de "los otros".

Pero más allá del consenso que se haya podido alcanzar sobre este tema, durante las últimas tres décadas se ha observado un creciente reconocimiento de su complejidad e importancia. De allí que haya surgido el interés de vincular la etnicidad a las estadísticas oficiales, aunque las definiciones de los cuestionarios y las preguntas censales actuales sobre la etnia y la raza dependen de las interpretaciones políticas, las agendas y las motivaciones que llevan a los Estados de cada país a emprender esa tarea. Por lo tanto, son múltiples los sesgos derivados de las decisiones operativas que se toman, y ello da como resultado que las estadísticas oficiales sobre los grupos étnicos sean muy poco fiables y, sobre todo, que no haya posibilidad de establecer comparaciones entre los países o que esa posibilidad sea escasa.

Como estrategia para superar lo anterior es preciso redefinir los cuestionarios de los censos o las encuestas de hogares a fin de desligar los elementos que integran la etnicidad y de reunificarlos en una medida integral de esta que aquí se denomina factor de etnicidad (fet).

La exclusión social, por su parte, es un concepto y un fenómeno que las ciencias sociales aún están construyendo y reconstruyendo debido a la dispersión de acepciones y discursos que denotan diferentes realidades para un mismo proceso. Sin embargo, la exclusión social podría definirse "como un conjunto de mecanismos estructurales [e institucionales] que impiden [de forma sistemática] a ciertos grupos sociales participar plenamente en las esferas económica, social, política y cultural de la sociedad" (Valdivia, Benavides y Torero, 2007, pág. 604).

Debido a que la exclusión social es un fenómeno multidimensional, multicausal, estructural y dinámico que también se define por la acumulación de déficits (privaciones) que se interrelacionan y se retroalimentan entre sí, el concepto abarca muchos de los elementos que Alkire y Foster (2007) utilizan 
en el cálculo de la pobreza multidimensional. Por tanto, en esta investigación se propone el grado de exclusión social (ges) como medida alternativa y como variación del índice de pobreza multidimensional (IPM) que utiliza el DANE en Colombia, a partir de privaciones de los hogares en 15 variables y 5 dimensiones, según un umbral normativo (zj) establecido para cada variable.

Los datos dan cuenta de que Colombia es un país muy étnico, ya que en el período analizado el factor de etnicidad es de aproximadamente 0,46 en una escala de 0 a 1. Los datos también indican que, tal como sugiere la teoría, la etnicidad es mayor en el caso de los tonos de piel más oscuros $(c p>0,45)$, de quienes se autoadscriben a algún grupo étnico, de los inmigrantes y de los hogares rurales. Así mismo, los datos muestran que el indicador de exclusión social del país alcanza un valor promedio de un 55\% de privación en los hogares. El indicador exhibió un descenso importante en 2015, cuando hubo una mejora general de las condiciones de vida del país, pero volvió a crecer en los años subsiguientes. Además, este indicador afecta más a las zonas rurales y a los hogares en que la etnicidad es mayor, bien por el color de piel o por la pertenencia a grupos étnicos.

En Colombia, los procesos más intensos de exclusión social definitivamente se observan en los grupos o sectores sociales cuyo factor de etnicidad es mayor. Esto no quiere decir que en los países no haya otras líneas de exclusión, como el género, la edad o la religión. Lo que sí parece querer decir es que las diferencias étnicas, raciales y de nacionalidad se encuentran entre los factores más evidentes de exclusión social. Los resultados dan cuenta de una relación directa e importante entre el factor de etnicidad (fet) y el grado de exclusión social (ges) en el país, pues cuando el primero se incrementa 1 punto porcentual, el segundo aumenta 7 puntos porcentuales con un grado de confianza del 95\%. Del mismo modo, tener un tono de piel más oscuro, autoadscribirse a un grupo étnico, ser inmigrante y vivir en zonas rurales aumenta el grado de exclusión. Por otra parte, tener un mayor nivel de educación o de ingreso per cápita contrarresta ese efecto. Finalmente, el género del jefe de hogar no incide de forma significativa en el nivel de exclusión social.

\section{Bibliografía}

Alkire, S. y J. Foster (2007), "Counting and multidimensional poverty measurement", OPHI Working Papers, $N^{\circ} 7$, Oxford Poverty and Human Development Initiative (OPHI).

Antón, J. y F. Del Popolo (2009), "Visibilidad estadística de la población afrodescendiente de América Latina: aspectos conceptuales y metodológicos", Afrodescendientes en América Latina y el Caribe: del reconocimiento estadístico a la realización de derechos, serie Población y Desarrollo, № 87 (LC/L.3045-P), J. Antón y otros, Santiago, Comisión Económica para América Latina y el Caribe (CEPAL).

Arango, J. (2003), "Inmigración y diversidad humana: una nueva era en las migraciones internacionales", Revista de Occidente, № 268.

Banco Mundial (2014), Inclusión social: clave de la prosperidad para todos. Resumen, Washington, D.C.

Bello, Á. y M. Rangel (2000), Etnicidad, "raza" y equidad en América Latina y el Caribe (LC/R.1967/Rev.1), Santiago, Comisión Económica para América Latina y el Caribe (CEPAL).

Blanco, C. (2000), Las migraciones contemporáneas, Madrid, Alianza Editorial.

CEPAL (Comisión Económica para América Latina y el Caribe) (2008), Balance Preliminar de las Economías de América Latina y el Caribe, 2008 (LC/G.2401-P), Santiago.

CONAPO (Consejo Nacional de Población) (2009), "Migración Internacional", Informe de Ejecución: Programa de Acción de la Conferencia Internacional sobre la Población y el Desarrollo 1994-2009, Ciudad de México.

Dagum, C., R. Gambassi y A. Lemmi (1992), "New approaches to the measurement of poverty", Poverty Measurement for Economies in Transition in Eastern European Countries, Varsovia, Asociación de Estadística de Polonia/Oficina Central de Estadística.

Domínguez, J. y J. Núñez (2013), "Exclusión social nos fogares españois: un estudo comparativo rexional durante o período 2004-2008", Revista Galega de Economía, vol. 22, núm. extraordinario, septiembre.

Estivill, J. (comp.) (2004), Pobreza y exclusión en Europa: nuevos instrumentos de investigación, Barcelona, Hacer. 
Fernández de Labastida, I. (s/f), "Tema 6: etnicidad e inmigración", Universidad del País Vasco [en línea] https://ocw.ehu.eus/pluginfile.php/53497/mod_resource/content/1/Tema_6._Etnicidad_e_inmigracion.pdf.

Figueroa, A., T. Altamirano y D. Sulmont (1996), Exclusión social y desigualdad en el Perú, Lima, Organización Internacional del Trabajo (OIT).

Gacitúa, E. y S. Davis (2000), "Introducción: pobreza y exclusión social en América Latina y el Caribe", Exclusión social y reducción de la pobreza en América Latina y Caribe, E. Gacitúa, C. Sojo y S. Davis (eds.), San José/Washington, D.C., Facultad Latinoamericana de Ciencias Sociales (FLACSO)/Banco Mundial.

Godínez-Montoya, L., E. Figueroa-Hernández y F. Pérez-Soto (2014), "Nueva reconfiguración de la inmigración internacional: el caso de España", Hitos demográficos del siglo XXI: migración internacional, J. González Becerril, B. Montoya Arce y A. Barreto Villanueva (coords.), Toluca, Universidad Autónoma del Estado de México.

Goldberg, C. (2007), "Reflexiones en torno a la medición de la etnicidad en censos y encuestas", documento presentado en las IX Jornadas Argentinas de Estudios de Población, Huerta Grande, Asociación de Estudios de Población de la Argentina (AEPA), 31 de octubre a 2 de noviembre.

Good Gingrich, L. y N. Lightman (2015), "The empirical measurement of a theoretical concept: tracing social exclusion among racial minority and migrant groups in Canada", Social Inclusion, vol. 3, № 4, julio.

Hernández Pedreño, M. (coord.) (2008), "Pobreza y exclusión en las sociedades del conocimiento”, Exclusión social y desigualdad, M. Hernández Pedreño (coord.), Murcia, Servicio de Publicaciones de la Universidad de Murcia.

Hopenhayn, M. y Á. Bello (2000), "Tendencias generales, prioridades y obstáculos en la lucha contra el racismo, la discriminación racial, la xenofobia y las formas conexas de intolerancia. América Latina y el Caribe", documento presentado en el Seminario Regional de Expertos para América Latina y el Caribe sobre Medidas Económicas, Sociales y Jurídicas para Luchar contra el Racismo, con Referencia Especial a los Grupos Vulnerables, Santiago, 25 a 27 de octubre.

IGOP (Instituto de Gobierno y Políticas Públicas) (2003), Un paso más hacia la inclusión social: generación de conocimiento, políticas y prácticas para la inclusión social, Madrid, Plataforma de ONGs de Acción Social.

Jiménez Ramírez, M. (2008), "Aproximación teórica de la exclusión social: complejidad e imprecisión del término. Consecuencias para el ámbito educativo”, Estudios Pedagógicos, vol. XXXIV, № 1, Valdivia, Universidad Austral de Chile.

Lenoir, R. (1974), Les exclus: un Française sur dix, París, Éditions du Seuil.

Loktieva, I. (2016), "Approaches to empirical analysis of social exclusion: international comparison", Economics and Sociology, vol. 9, № 2.

Morning, A. (2008), "Ethnic classification in global perspective: a cross-national survey of the 2000 census round", Population Research and Policy Review, vol. 27, febrero.

Ñopo, H., J. Saavedra y M. Torero (2004), "Ethnicity and earnings in urban Peru", Discussion Paper Series, No 980, Bonn, Institute for the Study of Labor.

Oommen, T. (1994), "Race, ethnicity and class: an analysis of interrelations", International Social Science Journal, № 139, febrero.

Peligero Escudero, P. (2006), "Inmigración y mercado laboral", El control de los flujos migratorios hacia España: situación actual y propuestas de actuación, Documentos de Seguridad y Defensa, № 6, Centro Superior de Estudios de la Defensa Nacional.

Rangel, M. (2004), "Género, etnicidad, pobreza y mercado de trabajo en Bolivia, Ecuador, Guatemala y Perú", Desigualdades entrecruzadas: pobreza, género, etnia y raza en América Latina, M. E. Valenzuela y M. Rangel (eds.), Santiago, Organización Internacional del Trabajo (OIT).

Raya Díez, E. (2006), Indicadores de exclusión social: una aproximación al estudio aplicado de la exclusión, Bilbao, Universidad del País Vasco.

Schkolnik, S. (2009), "La inclusión del enfoque étnico en los censos de población de América Latina”, Notas de Población, № 89 (LC/G.2427-P), Santiago, Comisión Económica para América Latina y el Caribe (CEPAL).

Schkolnik, S. y F. Del Popolo (2006), "Los censos y los pueblos indígenas en América Latina: una metodología regional", Pueblos indígenas y afrodescendientes de América Latina y el Caribe: información sociodemográfica para politicas y programas, Documentos de Proyectos (LC/W.72), Santiago, Comisión Económica para América Latina y el Caribe (CEPAL).

Stavenhagen, R. (2002), "La diversidad cultural en el desarrollo de las Américas: los pueblos indígenas y los Estados nacionales en Hispanoamérica", Organización de los Estados Americanos (OEA) [en línea] http://www.oas.org/udse/espanol/cpo_cult_public.asp. 
Tedesco, L. (2010), "Latinoamericanos en España: de la integración al retorno”, Inmigración latinoamericana en España: el estado de la investigación, A. Ayuso y G. Pinyol (eds.), Barcelona, Fundación CIDOB.

Telles, E. (2014), Pigmentocracies: Ethnicity, Race, and Color in Latin America, Chapel Hill, The University of North Carolina Press.

Telles, E. y L. Steele (2012), "Pigmentocracia en las Américas: ¿cómo se relaciona el logro educativo con el color de piel?", Perspectivas desde el Barómetro de las Américas: 2012, № 73, Proyecto de Opinión Pública de América Latina (LAPOP).

Torero, M. y otros (2004), "La economía de la exclusión social en Perú: ¿un muro invisible?", Inclusión Social y Desarrollo Económico en Latina América, M. Buvinic', J. Mazza y J. Pungiluppi (eds.), Washington, D.C., Banco Interamericano de Desarrollo (BID)/Johns Hopkins University Press.

Trouillot, M.-R. (2000), "Exclusión social en el Caribe", Exclusión social y reducción de la pobreza en América Latina y Caribe, E. Gacitúa, C. Sojo y S. Davis (eds.), San José/Washington, D.C., Facultad Latinoamericana de Ciencias Sociales (FLACSO)/Banco Mundial.

Valdivia, N. (2011), El uso de categorías étnico/raciales en censos y encuestas en el Perú: balance y aportes para una discusión, Documento de Investigación, № 60, Lima, Grupo de Análisis para el Desarrollo (GRADE).

Valdivia, N., M. Benavides y M. Torero (2007), "Exclusión, identidad étnica y políticas de inclusión social en el Perú: el caso de la población indígena y la población afrodescendiente”, Investigación, políticas y desarrollo en el Perú, Lima, Grupo de Análisis para el Desarrollo (GRADE).

Wade, P. (2011), "Raza y naturaleza humana", Tabula Rasa, № 14, enero-junio. 